\title{
ANALIZA SADRŽAJA I ELEMENATA KULTURE U UDŽBENIKU ZA ENGLESKI JEZIK PIONEER
}

\begin{abstract}
APSTRAKT: Ovaj rad se bavi analizom i procenom prisutnosti elemenata anglofone, domaće (lokalne) i međunarodne kulture u udžbeniku za engleski jezik - Pioneer B2, MM Publications (2015). Metodom analize sadržaja udžbenika, teme kao što su umetnost, muzika, istorija, književnost, običaji, geografija, sport i slobodno vreme dele se u jednu od tri kategorije, anglofona, domaća ili međunarodna kultura, koje se potom dalje tumače u svetlu elemenata površinske ili dubinske kulture. Kao velika prednost udžbenika ističe se širok raspon savremenih tema i interkulturalnih sadržaja što nesumnjivo doprinosi jačanju interkulturalne kompetencije učenika, a prisustvo elementa dubinske kulture drugih nacija podstiče razvoj globalne svesti. Nedostatak ovog udžbenika ogleda se u odsustvu elemenata ciljne kulture na oba nivoa. Autentični materijali nisu sastavni deo sadržaja, te su na taj način učenici uskraćeni za izvorne jezičke materijale koji bi im mogli omogućiti da ostvare dodir sa segmentima stranog jezika koji će im biti potrebni u daljem obrazovnom i profesionalnom angažovanju.
\end{abstract}

Ključne reči: engleski jezik, anglofona kultura, površinska i dubinska kultura, Pioneer, udžbenik.

\section{ANALYSIS OF ELEMENTS OF CULTURE IN THE ENGLISH LANGUAGE TEXTBOOK PIONEER}

ABSTRACT: This paper deals with the analysis of elements of Anglophone, domestic (local) and international culture in the textbook for English language learning, Pioneer B2, MM Publications (2015). Topics such as art, music, history, literature, customs, geography, sports and leisure activites are divided into one of three categories in the process of content analysis: Anglophone, domestic or international culture, which are further interpreted in the light of surface or deep culture. An advantage of the textbook is a wide range of contemporary topics and intercultural contents, which contribute to strengthening the intercultural competence of students; the presence of elements of deep culture of other nations encourages the development of global awareness. The disadvantage of this textbook is reflected in the absence of authentic materials and elements of deep and surface target culture, which deprives students of original language materials that they will need in further educational and professional engagement.

Key words: English language, Anglophone culture, surface and deep culture, Pioneer, textbook. 


\section{UVOD}

U kontekstu učenja stranog jezika u razrednoj situaciji slobodno se može reći da su udžbenici osnovno sredstvo i glavno pomagalo nastavnicima na svim nivoima obrazovanja - od osnovnoškolskog do univerzitetskog. S obzirom da se nastava stranog jezika u razrednoj situaciji temelji na temama koje se obrađuju u udžbeniku koji nastavnik koristi u nastavi, nesumnjivo je da će taj nastavni materijal imati uticaj na učenike, na njihovo poimanje socijalne, verske, kulturne i jezičke raznolikosti. Na sličan način učenici dalje šire informacije o kulturi stranog jezika koji uče kroz pojedinosti o kojima saznaju kroz razne tekstove, članke i vežbe. To je od vitalnog značaja za učenje jezika, jer se na taj način razvijaju pozitivni stavovi, jača mogućnost učenja i usvajanja stranog jezika, ali i rađa empatija ka drugim nacijama kroz upoznavanje sa različitim kulturama, načinima i stilovima života. Mnogi će se složiti sa mišljenjem da udžbenici čine samu srž procesa učenja stranog jezika, ne samo zbog jezičkih elemenata kojima se bave, već i zbog kulturoloških normi koje imaju značajnu ulogu u procesu oblikovanja kulturnih i društvenih stavova koji postaju sastavni deo opšte kulture i ponašanja učenika (Azizifar, Khoosha, Lotfi 2011: 88).

Međutim, postoje različita stanovišta u vezi sa kulturnim i društvenim sadržajima u udžbenicima za učenje stranog jezika. Dok jedni smatraju da je učenje stranog jezika neodvojivo od elemenata kulture (Tomlinson 2008; Byram 1990; Byram, Flemming 1998; Kramsch, Sullivan 1996; McKay 2004, Suzić, RadićBojanić 2018), te da udžbenici koji se mahom baziraju na obradi jezičkog sadržaja dovode do nesnalaženja učenika u autentičnim situacijama, drugi odbacuju ovu zamisao navodeći da se engleski jezik pretvara u jezik lingua franca, te da baš iz tog razloga treba da se uči nezavisno od elemenata bilo kakve kulture (Alptekin 2002; Jenkins 2000; Seidlhofer 2001). Pored toga, postoji i treća strana koja tvrdi da prisutnost elemenata kulture u udžbenicima za strani jezik može da razvije negativne stavove u vezi sa društvenim i kulturnim sadržajima ciljnog jezika (Sardi 2002: 101).

Uzimajući u obzir sve navedene argumente, teško je reći koji pristup ima prednost nad ostalima, stoga je cilj ovog rada da se kroz analizu udžbenika za engleski jezik (koji se u ovom slučaju koristi kao udžbenik na tercijarnom nivou obrazovanja) analiziraju elementi anglofone, domaće, tj. lokalne i međunarodne kulture kako bi se utvrdilo da li se sadržaj ovog udžbenika zasniva na sociolingvističkom pristupu prema kome su elementi kulture ciljnog jezika nerazdvojni od nastave jezika kao takve. S obzirom da se pomenuti udžbenik 
koristi na tercijarnom nivou obrazovanja, dakle koriste ga studenti starosti od 18 do 20 godina, elementi lokalne i međunarodne kulture su takođe uzeti u obzir kako bi se videlo da li se učenicima daje mogućnost multikulturalnog pristupa, odnosno poređenja različitih kultura, da li oni diskutuju o kulturama, uočavaju sličnosti i razlike, da li nastavnici podstiču učenike na razumevanje kako svoje tako i kulture drugih nacija. Ukoliko se elementi kulture ne baziraju isključivo na površinskoj kulturi, već se kroz analizu elemenata kulture uočavaju segmenti koji se odnose na dubinsku kulturu neke nacije, na taj način dolazi do jačanja međuljudskih odnosa i premošćivanja jaza između različitih kulturnih sredina (Steiner, Nash, Chase 2008: $88)$.

\section{TEORETSKA SHVATANJA O JEZIKU I KULTURI}

U okviru nastave stranog jezika koja se odvija u razrednoj situaciji neretko je akcenat stavljen na lako uočljive, tzv. površinske elemente kulture (Hinkel 2001: 445) koji karakterišu određenu naciju. Tako se u materijalima za učenje stranog jezika često nalaze opisi praznika, turističkih znamenitosti, poznatih ličnosti, hrane, pića i slično. Međutim, ovi površinski elementi kulture nisu dovoljni da učenici shvate određenu kulturu, jer se oni fokusiraju na akumulaciju opštih statičnih informacija ne baveći se osnovnim sociokulturnim interakcijama koje se javljaju u autentičnim situacijama.

Kulturu ne čine samo materijalne stvari, već i stanje svesti, vrednosti i moral ljudi, način na koji razmišljaju i zamišljaju svet i svoje živote u njemu (Suzić, Radić-Bojanić 2018: 514). Stoga, dubinsku kulturu, za razliku od površinske, odlikuje ono nevidljivo što karakteriše neku regiju, grupu ljudi ili subkulturu, njihove društvene norme, način života, verovanja i vrednosti. Prema tome, nije redak slučaj da elementi dubinske kulture nailaze na nerazumevanje, konfuziju i osudu.

S obzirom da je učenje jezika usko povezano sa stavovima učenika o jeziku koji uče (Starks, Paltridge 1996: 218), razvoj pozitivnih stavova učenika o kulturi jezika koji se uči jedan je od faktora koji utiče na razvoj međukulturnog razumevanja. Drugim rečima, pre nego što počnu da uče strani jezik, učenici moraju da budu otvoreni za razumevanje i uvažavanje elemenata kulture drugih naroda. Negativni stavovi ka drugim kulturama se uglavnom rađaju kod osoba koje svet posmatraju kroz prizmu sopstvene kulture i njenih vrednosti, što dovodi do razvoja stereotipa i etnocentrizma (Karimpur 2000, prema Ahmad H., Shah S. R. 2014: 88). Slično tome, Gardner veruje (Gardner 1985) da je motivacija za učenje stranog jezika određena upravo stavom učenika prema kulturi ciljnog jezika. 
Naime, negativni stavovi učenika o kulturi ciljnog jezika mogu dovesti do smanjenja motivacije i želje da se strani jezik nauči, što kao posledicu može imati nezadovoljavajuća dostignuća u poznavanju stranog jezika.

$\mathrm{Ne}$ treba zaboraviti ni značaj upotrebe autentičnih materijala $u$ udžbenicima koji se koriste u nastavi stranih jezika, jer ovakvi materijali omogućavaju učenicima da upoznaju jezik kroz stvarne životne situacije u odgovarajućem kulturnom i socijalnom kontekstu (Ketabi, Shomossi 2007: 149). Autentični materijali su uglavnom prisutni kao pisani materijali (novinski članci, časopisi, knjige, jelovnici i slično) i usmeni sadržaji (audio-materijali i videomaterijali). Ovakvi sadržaji su neretko dopunjeni mapama, slikama i ilustracijama stvarnih mesta i događaja što upotpunjuje širok spektar štampanih i govornih informacija koje se nalaze u udžbenicima za učenje stranog jezika (Glišović 2014: 239).

\section{METODOLOGIJA}

$\mathrm{Na}$ osnovu prethodno iznetih teorijskih postavki, kroz analizu sadržaja udžbenika za učenje engleskog jezika Pioneer, MM Publications, na nivou B2, pokušavamo da identifikujemo prisutnost elemenata anglofone, domaće (lokalne) i međunarodne kulture. Zatim te identifikovane elemente analiziramo kroz prizmu površinske i dubinske kulture. Cilj ovakve uporedne analize je da se ispita način na koji su dati elementi uvršteni u lekcije, te mogu li da pomognu učenicima da razviju interkulturalnu kompetenciju zbog koje bi postali svesni kulturoloških razlika u društvu u kojem žive. Analiza sadržaja udžbenika izvršena je retrospektivnom analizom, tj. analizom sadržaja udžbenika koji je u upotrebi (Skopinskaja 2003) na Univerzitetu Singidunum u Srbiji. U pitanju je udžbenik za učenje engleskog jezika na tercijarnom nivou obrazovanja Pioneer, B2, MM Publications (2015). Ovaj udžbenik se koristi na Univerzitetu Singidunum kao primarna literatura na prvoj i drugoj godini studija. Analizom sadržaja koji se obrađuje u ovom udžbeniku doći ćemo do odgovora na sledeća istraživačka pitanja:

1. Da li udžbenik sadrži dovoljan broj savremenih tema koje bi učenicima sekundarnog i tercijarnog obrazovanja bile interesantne i stimulativne?

2. U kom odnosu su u udžbeniku zastupljeni elementi anglofone, domaće i međunarodne kulture?

3. Da li se u udžbeniku koriste autentični materijali?

4. Da li teme obrađene u udžbeniku za učenje engleskog jezika Pioneer B2 sadrže elemente površinske i dubinske anglofone kulture? 
Metoda analize sadržaja korišćena je pri analizi elemenata kulture, tako što je svaka stranica udžbenika detaljno pregledana, s ciljem da se uoče sve aktivnosti u koje su inkorporirani elementi kulture. Dobijeni rezultati su potom kategorisani prema temama, a svaka tema je klasifikovana u jednu od tri kategorije: anglofona kultura, domaća kultura i međunarodna kultura. Svi statični aspekti kulture koju udžbenik obrađuje, kao što su praznici, geografski pojmovi, poznate ličnosti, hrana, piće i slično, posmatrani su potom kao elementi površinske kulture, dok su nevidljivi aspekti koji karakterišu neku regiju, društvene norme, vrednosti i verovanja posmatrani kao elementi dubinske kulture.

\section{ANALIZA PODATAKA}

Osnovni cilj rada je da se kroz analizu sadržaja udžbenika Pioneer za učenje engleskog jezika na nivou B2 utvrdi koji su elementi anglofone (ciljne) kulture, domaće (lokalne) i međunarodne kulture zastupljeni i u kojoj meri. Potom se za svaki od navedenih elemenata utvrđuje da li pripada kategoriji površinske ili dubinske kulture. Dobijeni rezultati predstavljeni su u Tabeli 1.

\begin{tabular}{|c|c|c|c|}
\hline Kategorija & Anglofona kultura & Domaća kultura & Međunarodna kultura \\
\hline \multicolumn{4}{|c|}{ Hrana i piće } \\
\hline Život, rad i & - britanski i & & - nekonvencionalne škole \\
\hline škola & američki engleski & & (Afrika, Amerika, Kanada) \\
\hline & & & - britanski i američki izrazi \\
\hline $\begin{array}{l}\text { Slobodno } \\
\text { vreme }\end{array}$ & - idiomi & & \\
\hline Sport & - idiomi & & $\begin{array}{l}\text { - ultramaratoni (Kanada, } \\
\text { Amerika, Arktik, Sahara, Peru) } \\
\text { - istorija pilatesa (SAD) }\end{array}$ \\
\hline Geografija & & & $\begin{array}{l}\text { - zastave i amblemi (Kina, } \\
\text { USA, Bangladeš, Rusija, } \\
\text { Švajcarska, Belize, Meksiko, } \\
\text { Turska, Italija, Nepal) } \\
\text { - Brazil, Egipat, Japan } \\
\text { (gramatičke vežbe) } \\
\text { - Venecija (vežbe čitanja) } \\
\text { - Kenija (vežbe slušanja) }\end{array}$ \\
\hline $\begin{array}{l}\text { Umetnost, } \\
\text { muzika, } \\
\text { film }\end{array}$ & $\begin{array}{l}\text { Isečci iz književnih } \\
\text { dela: } \\
\text { - The jungle book, }\end{array}$ & $\begin{array}{l}\text { Opiši nacionalni } \\
\text { festival svoje zemlje, } \\
\text { turistička }\end{array}$ & $\begin{array}{l}\text { - nacionalni multikulturalni } \\
\text { festival u Australiji } \\
\text { - film Now you see me, }\end{array}$ \\
\hline
\end{tabular}




\begin{tabular}{|c|c|c|c|}
\hline & $\begin{array}{l}\text { Radjard Kipling, } \\
\text { engleski književnik } \\
\text { - Karlajl muzej } \\
\text { (Carlyle Museum) } \\
\text { (vežba pisanja) } \\
\text { - Šerlok Holms } \\
\text { (Sherlock Holmes) } \\
\text { (vežba čitanja) }\end{array}$ & $\begin{array}{l}\text { znamenitost (vežba } \\
\text { pisanja) }\end{array}$ & $\begin{array}{l}\text { američki film } \\
\text { - Leonardo da Vinči, italijanski } \\
\text { slikar i pronalazač }\end{array}$ \\
\hline $\begin{array}{l}\text { Savremene } \\
\text { teme }\end{array}$ & $\begin{array}{l}\text { - tradicionalno i } \\
\text { nekonvencionalno } \\
\text { obrazovanje u Velikoj } \\
\text { Britaniji } \\
\text { - Erozija obale u } \\
\text { severnoistočnoj } \\
\text { Britaniji }\end{array}$ & $\begin{array}{l}\text { - Koje dobrotvorne } \\
\text { organizacije postoje } \\
\text { u tvojoj zemlji? } \\
\text { (vežba govorenja) } \\
\text { - Da li je problem } \\
\text { vandalizma čest u } \\
\text { tvojoj zemlji? (vežba } \\
\text { pisanja) } \\
\text { - Da li je problem } \\
\text { beskućništva prisutan } \\
\text { u tvojoj zemlji? } \\
\text { (vežba govorenja) }\end{array}$ & $\begin{array}{l}\text { - tekst na temu Šta putovanje } \\
\text { čini autentičnim? (vežba } \\
\text { čitanja) } \\
\text { - aqua alta u Veneciji (vežba } \\
\text { čitanja) } \\
\text { - The Big Issue - novine koje } \\
\text { se objavljuju na četiri } \\
\text { kontinenta (vežba čitanja) }\end{array}$ \\
\hline Istorija & & & $\begin{array}{l}\text { - Citati poznatih osoba: } \\
\text { Marcus Garvey, aktivista sa } \\
\text { Jamajke; J. H. Pilates, nemački } \\
\text { gimnastičar i bodibilder; } \\
\text { Robert Evans, američki } \\
\text { producent; J. Gagarin, N. } \\
\text { Armstrong (pominju se u vežbi } \\
\text { čitanja) }\end{array}$ \\
\hline Običaji & & $\begin{array}{l}\text { Opiši običaj svoje } \\
\text { zemlje (vežba } \\
\text { govorenja) }\end{array}$ & $\begin{array}{l}\text { - Pominju se običaji iz } \\
\text { sledećih zemalja: Australija, } \\
\text { Indija. } \\
\text { - 1. april - običaji u raznim } \\
\text { zemljama }\end{array}$ \\
\hline $\begin{array}{l}\text { Autentični } \\
\text { materijali }\end{array}$ & $\begin{array}{l}\text { - Isečak iz književnog } \\
\text { dela Jungle book }\end{array}$ & & \\
\hline
\end{tabular}

Tabela 1. Klasifikacija tema obuhvaćenih udžbenikom Pioneer

Kako se u istraživanje krenulo s istraživačkim zadatkom $D a$ li udžbenik sadrži dovoljan broj savremenih tema koje bi učenicima sekundarnog i tercijarnog obrazovanja bile interesantne $i$ stimulativne?, autorka na osnovu tema 
prezentovanih u Tabeli 1. izvodi zaključak da su teme predstavljene u okviru udžbenika Pioneer raznovrsne, savremene i dovoljno motivacione kako bi zainteresovale učenike za čitanje, slušanje i pisanje na stranom jeziku. Od savremenih tema posebno se izdvajaju teme u vezi sa tradicionalnim i nekonvencionalnim obrazovanjem, teme u vezi sa klimatskim promenama i njihovim uticajem na biljni i životinjski svet, te teme koje se tiču kvaliteta savremenog života s obzirom na porast stope kriminala i povećan broj socijalno ugroženog stanovništva. Tekstovi ovog tipa obrađeni su kroz sve četiri jezičke veštine. Dakle, teme i izrazi koji su u vezi sa ovom tematikom, provlače se kroz vežbe pisanja, slušanja, čitanja i govorenja. Teme su savremene, aktuelne, a samim tim i dovoljno stimulativne da navedu učenike da o istima dodatno razmisle ili ih istraže.

U odgovoru na drugo istraživačko pitanje - U kom odnosu su u udžbeniku zastupljeni elementi ciljne, domaće $i$ međunarodne kulture? autorka analizom sadržaja predstavljenog u Tabeli 1. dolazi do iznenađujućeg zaključka. Kada se radi o prisutnosti elemenata anglofone, tj. ciljne kulture uočava se da se u kategorijama hrana i piće, život, rad, škola, slobodno vreme, sport, geografija, istorija, običaji, autentični materijali ne pominje nijedan tekst koji bi verodostojno predstavio anglofonu kulturu $\mathrm{u}$ navedenim kategorijama. Kategorije sport $\mathrm{i}$ slobodno vreme, u kontekstu elemenata anglofone kulture, obrađene su kroz vežbu vokabulara gde se spominju idiomi karakteristični za engleski jezik, a koji u sebi sadrže fraze koje su vezane sa određene sportove, npr. below the belt (boks), the ball is in your court (tenis). U okviru kategorije škola autorka takođe ne pronalazi elemente anglofone kulture koji bi opisali sistem školovanja, škole, prestižne engleske univerzitete, običaj nošenja školskih uniformi i slično, već samo jednu vokabularnu vežbu koja se odnosi na razlike između britanskog i američkog engleskog jezika, npr. mark - grade, semester - term i slično. Kada su u pitanju elementi domaće kulture, iako udžbenik ne sadrži tekstove koji se eksplicitno tiču običaja, načina života i tema u vezi sa našim podnebljem, uočava se da se u okviru sekcija koje se odnose na vežbe govorenja od učenika traži da opišu znamenitosti i običaje sopstvene zemlje, navedu goruća socijalna i ekonomska pitanja sa kojima se njihova zemlja suočava. Sem u navedenim vežbama govorenja, elementi domaće kulture nisu prisutni ni u jednom drugom segmentu udžbenika.

Što se tiče elemenata međunarodne kulture, primetno je da udžbenik obiluje istima (Tabela 1). U gotovo svim navedenim kategorijama spominju se elementi međunarodne kulture, s izuzetkom kategorija hrana i piće, slobodno 
vreme i autentični materijali. Elementi međunarodne kulture provlače se kroz sve četiri jezičke veštine, a posebno su prisutni u vežbama čitanja. Primetno je da se u okviru vežbi slušanja elementi međunarodne kulture slabije pominju, već se multikulturalnost provlači kroz razgovore, intervjue i razmenu mišljenja studenata različitih etničkih grupa koji govore o temama koje su u vezi sa obrađivanom celinom (npr. klimatske promene, značaj zdrave ishrane i slično).

Treće istraživačko pitanje odnosi se na autentične materijale i glasi: Da li se u udžbeniku koriste autentični materijali? Na osnovu detaljne analize sadržaja udžbenika i uvidom u Tabelu 1, nije uočeno prisustvo nijednog autentičnog materijala, sem isečka iz književnog dela Knjiga o džungli (engl. Joungle Book).

U okviru četvrtog istraživačkog pitanja - Da li teme obrađene u udžbeniku za učenje engleskog jezika Pioneer B2 sadrže elemente površinske $i$ dubinske anglofone kulture? pronalaze se elementi i površinske i dubinske kulture. Elementi površinske kulture vidljivi su u sekcijama koje pokrivaju oblast međunarodne kulture, gde se spominju zastave i amblemi svetskih zemalja (Amerika, Kina, Nepal, itd.), poznate ličnosti (Leonardo da Vinči, Jurij Gagarin, Robert Evans), filmovi (engl. Now you see me), fiktivni likovi (Šerlok Holms). Elementi dubinske kulture prisutni su i u vežbama pisanja i govorenja, gde se od učenika traži da opišu običaje, socijalne probleme (kriminal, siromaštvo), autentično doživljavanje neke destinacije (engl. How to have authentic travel experinece). Elementi dubinske kulture su prisutni i u izjavama istorijskih, poznatih ličnosti (Markus Garvi, J. H. Pilates, Robert Evans) koje su dovoljno intrigantne da pokrenu debate i razmenu mišljenja (npr. A people without the knowledge of their past history, origin and culture is like a tree without roots ${ }^{1}$; Markus Garvi).

\section{ZAKLJUČAK}

$\mathrm{Na}$ osnovu detaljne analize sadržaja udžbenika Pioneer B2 izvodi se zaključak da udžbenik obiluje savremenim temama koje su od opšteg značaja za učenike stranog jezika starije dobi (starije tinejdžerske godine i adolescenti). Sadržaj se bazira na aktuelnim temama koje su u jednakoj meri prisutne kroz sve četiri jezičke veštine. Teme prate tehnološka otkrića, savremene pristupe putovanju i obrazovanju, bave se ozbiljnim pitanjima od javnog značaja kako na lokalnom tako i na međunarodnom nivou. Obrađene teme su interesantne i prijemčive, te čine dobru osnovu za dalji samostalni istraživački rad.

\footnotetext{
${ }^{1}$ Ljudi bez znanja o svojoj prošlosti, poreklu i kulturi su poput drveta bez korena.
} 
Prednost materijala zastupljenih u okviru ovog udžbenika ogleda se i kroz mnoštvo tema u vezi sa elementima međunarodne kulture. Kroz niz vežbi čitanja, slušanja i pisanja učenici se upoznaju sa znamenitostima drugih kultura, pominju se istorijske ličnosti, festivali, događaji, opisuju se socijalni problemi, daju informacije o uticaju klimatskih promena na određene delove sveta, te se, prvenstveno kroz vežbe čitanja učenici upoznaju sa karakteristikama drugih nacija, kultura i njihovim problemima.

Elementi domaće kulture, iako nisu zastupljeni kroz tekstove i ilustracije, prisutni su u udžbeniku kroz zadatke koji se tiču vežbi govorenja. Zadaci su opšteg karaktera. Na primer, Opiši način na koji se u tvojoj zemlji obeležava 1. april. Zadaci ovog tipa prisutni su u većini tekstova - uglavnom nakon što je neka tema obrađena kroz vežbu čitanja, što daje mogućnost nastavniku stranog jezika da pokrene debatu i razmenu mišljenja među učenicima.

Elementi površinske i dubinske kulture su, po mišljenju autorke, odlično inkorporirani u jezičke sadržaje, podstiču učenike na iznošenje sopstvenog mišljenje i razvijanje stava o važnim životnim pitanjima kako svoje zemlje tako i zemalja u svetu. Elementi dubinske kulture su suptilno prisutni u vežbama čitanja i slušanja, na osnovu kojih se od učenika traži da iskažu svoje mišljenje o problemima sa kojima se ljudi susreću u drugim zemljama, a koji su deo dubinske kulture određene nacije, te da potom diskutuju o prisutnosti takvih problema $\mathrm{u}$ svojoj zemlji, npr. Are there homeless people in your country and what is being done to help them? ${ }^{2}$

Nedostaci koji su uočeni analizom predstavljenih sadržaja odnose se prvenstveno na izostanak elemenata anglofone kulture. Elementi ciljne kulture nisu predstavljeni niti kroz receptivne, niti kroz produktivne veštine, tako da učenici ni na koji način nisu izloženi uticaju ciljne kulture jezika koji uče. Interesantno je da čak i elementi površinske anglofone kulture, koji su gotovo neizostavan deo svakog udžbenika za učenje stranog jezika (hrana, piće, običaji, škola, sport), ne pronalaze svoje mesto u analiziranom udžbeniku. Neophodno je naglasiti još jedan veliki nedostatak uočen analizom sadržaja - a to je potpuni izostanak autentičnih materijala. Udžbenik ne sadrži nijedan isečak iz novina, časopisa, radio-snimak ili autentičan video-zapis koji bi učenicima omogućio da steknu uvid o načinu upotrebe određenih fraza i izraza u stvarnim životnim situacijama.

Na osnovu analiziranih sadržaja izvodi se zaključak da udžbenik Pioneer B2 obiluje savremenim temama i sadržajima, daje učenicima mogućnost da se

\footnotetext{
${ }^{2}$ Postoje li beskućnici u vašoj zemlji i šta se čini da im se pomogne?
} 
upoznaju sa temama od opšteg značaja na međunarodnom nivou, inkorporira elemente domaće i međunarodne kulture kroz vežbe čitanja, slušanja i pisanja. Kao posebno značajna stavka izdvaja se činjenica da se udžbenik u velikoj meri bavi elementima dubinske kulture, međunarodne i domaće, što treba da bude značajna stavka svakog udžbenika namenjenog učenju stranog jezika kod starijih polaznika. Kao glavni nedostatak udžbenika izdvaja se problem izostanka elemenata anglofone kulture, te odsustvo autentičnih materijala.

\section{LITERATURA}

Alptekin, C. (2002). Towards intercultural communicative competence in ELT. ELT Journal 56 (1): 57-64.

Azizifar, A., Koosha, M., Lotfi, A. (2011). An Analytical Evaluation of Iranian High School ELT Textbooks from 1970 to the present. The Journal of Asia TEFL 8 (1): 87-109.

Byram, M., Grundy, P. (2003). Context and Culture in Language Teaching and Learning. Clevedon: Multilingual Matters Ltd.

Byram. M., Fleming, M. (1998). Language learning in intercultural perspective: Approaches through drama and ethnography. Cambridge: Cambridge University Press.

Ellis, G. (1996). How culturally appropriate is the communicative approach? ELT Journal 50 (3): 213-128.

Gardener, R.C. (1985). Social Psychology and Second language learning: the Role of Atttitude and Motivation. London: Edward Arnold.

Glišović, I. (2014), Autentičan jezik u nastavi stranih jezika na nefilološkim fakultetima, Tematski zbornik radova Univerziteta u Nišu: Jezik, književnost i kultura 4: 236-247.

Hinkel, E. (2001). Building awareness and practical skills to facilitate crosscultural communication, in Teaching English as a second or foreign language, ed. M. Celce Murcia (Boston, MA: Heinle Cengage Learning): 443-459.

Jenkins, J. (2000). The Phonology of English as an International Language. Oxford: Oxford University Press.

Karimpur, A. (2000). Iranian EFL Learners' Attitudes Towards British and American English and their Effect on Their Listening Comprehension, prema Ahmad H., Shah S. R. (2014). EFL textbooks: exploring the suitability of textbook contents from EFL Teachers' perspective. VFAST Transactions on Education and Social Sciences (2) 1: 87-95. 
Ketabi, S., Shoomossi, N. (2007). A critical look at the concept of authenticity. Electronic Journal of Foreign Language Teaching 4 (1): 149-155.

Kramsch, C., Sullivan, P. (1996). Appropriate pedagogy. ELT Journal 50 (3): 199212.

McKay, S. L. (2004). Western Culture and the Teaching of English as an International Language. English Teaching Forum Online 42 (2): 10-15.

Sardi, C. (2002). On the Relationship between Culture and ELT. Studies about Languages 3: 101-107.

Seidlhofer, B. (2001). Closing a conceptual gap: the case for a description of English as a lingua franca. International Journal of Applied Linguistics 11: 134-158.

Skopinskaja, L. (2003). The role of culture in foreign language teaching materials: an evaluation from an intercultural perspective, in Incorporating intercultural communicative competence in language teacher education, ed. I. Lázár (European Centre for Modern Languages: Council of Europe Publishing): 39-69.

Starks, D., Paltridge, B. (1996). A note on using sociolinguistics methods to study non-native attitudes towards English. World Englishes 15 (2): 217-224.

Steiner, S. F., Nash, C. P., Chase, M. (2008). Multicultural Literature That Brings People Together. Reading Teacher 62 (1): 88-92.

Suzić, R., Radić-Bojanić, B. (2018) ; Elementi anglofone kulture u udžbenicima na tercijarnom nivou obrazovanja (FCE i CAE). Jezici i kulture $u$ vremenu $i$ prostoru 7 (1), ur. S. Gudurić, B. Radić-Bojanić (Novi Sad: Filozofski fakultet): 513-522.

Tomlinson, B. (2008). English Language Learning Materials: A Critical Review. London: Continuum. 
Radmila R. Suzić

Singidunum University

Faculty of Business in Belgrade

\section{ANALYSIS OF ELEMENTS OF CULTURE IN THE ENGLISH LANGUAGE TEXTBOOK PIONEER}

\section{Summary}

This paper deals with the analysis of elements of Anglophone, domestic (local) and international culture in an English textbook Pioneer B2, MM Publications (2015). Given that foreign language teaching in the classroom situation is based on topics covered in the textbook, this type of teaching material will have an impact on students, their understanding of social, religious, cultural and linguistic diversity. Therefore, using the method of content analysis, topics such as art, music, history, literature, customs, geography, sports and leisure activities are divided into three categories: Anglophone, domestic (local) or international culture. These topics are further interpreted in the light of elements of surface or deep culture in order to determine whether the content of this textbook is based on a sociolinguistic approach according to which the elements of the culture of L2 are inseparable from language teaching. Based on the analysed contents, it is concluded that the Pioneer textbook is rich in contemporary topics, gives students the opportunity to get acquainted with topics of general importance at the international level, incorporates elements of domestic and international culture through reading, listening and writing exercises. An advantage of the Pioneer textbook is the wide range of intercultural contents, which contributes to the strengthening of students' intercultural competence, and the presence of elements of deep culture encourages the development of global awareness. A particularly important component of the textbook is that it largely deals with elements of deep culture, both international and domestic, which should be a significant component of any textbook intended for learning a foreign language. The main shortcoming is the absence of elements of Anglophone culture and authentic materials which should have a central place in any English language learning textbook because it is a unique way to bring students closer to real-life situations in an appropriate cultural and social context.

Key words: English language, Anglophone culture, surface and deep culture, Pioneer, textbook.

Primljeno: 1. 5. 2021.

Prihvaćeno: 24. 8. 2021. 